\title{
The morphology of the proximal femur
}

Matthias Luger $r^{1,2,3^{*}}$ (D), Sandra Feldler ${ }^{1,2}$, Antonio Klasan ${ }^{1,2}$, Tobias Gotterbarm ${ }^{1,2}$ and Clemens Schopper ${ }^{1,2}$

\begin{abstract}
Background: Correct reconstruction of hip offset $(\mathrm{HO})$ and leg length are important for clinical-functional outcome and patient satisfaction in total hip arthroplasty (THA). The morphology of the proximal femur can pose a risk for increased leg length difference (LLD) in cementless straight-stem THA. We therefore wanted to evaluate, if this is also applicable in THA with a cementless meta-diaphyseal short stem.

Methods: In a retrospective study, 106 patients (index surgery 2014-2019) with unilateral THA and a morphologically healthy hip as a reference (Kellgren-Lawrence $\leq 1$ ) were included. The same cementless short stem with metadiaphyseal fixation and cementless press-fit cup was implanted. The proximal femur was rated by Dorr's classification, and subgroups were formed afterward. Measurements were carried out on preoperative and 3 months postoperative anterior-posterior radiographs of the pelvis. Kruskal-Wallis test, Fisher's exact test and binary logistic regression were performed to evaluate the influence of the anatomical shape on postoperative leg length difference and offset reconstruction.
\end{abstract}

Results: The Dorr type did not show any significance influence on $\operatorname{LLD}(p=0.532)$, or postoperative difference in femoral offset $(p=0.243)$, acetabular offset $(p=0.106)$ and hip offset $(p=0.698)$. Stem alignment $(p=0.705)$ and canal fill indices (CFI I: $p=0.321$; CFI II: $p=0.411$; CFI III: $p=0.478$ ) were also without significant differences. Logistic regression did not show any significant increased risk for a LLD $\geq 5 \mathrm{~mm}$ or $\geq 10 \mathrm{~mm}$ as well as $\mathrm{HO} \geq 5 \mathrm{~mm}$ or $\geq 10 \mathrm{~mm}$. Conclusion: Reconstruction of hip offset and postoperative leg length difference is not negatively influenced by Dorr type, canal flare index, cortical index and canal-to-calcar ratio in cementless short-stem THA. Implant positioning and canal fill are also not negatively affected by the anatomical shape of the proximal femur.

Level of evidence: Level IV.

Keywords: Short stem, Total hip arthroplasty, Dorr classification, Canal flare index, Leg length difference, Offset reconstruction

*Correspondence: Matthias.luger@kepleruniklinikum.at

1 Department for Orthopedics and Traumatology, Kepler University Hospital GmbH, Krankenhausstrasse 9, 4020 Linz, Austria

Full list of author information is available at the end of the article

\section{Introduction}

Total hip arthroplasty (THA) is a very successful and cost-effective surgical management of patients with end-stage osteoarthritis of the hip $[1,2]$. Correct reconstruction of the hip geometry is essential in THA in order to avoid adverse outcomes such as impingement original author(s) and the source, provide a link to the Creative Commons licence, and indicate if changes were made. The images or other third party material in this article are included in the article's Creative Commons licence, unless indicated otherwise in a credit line to the material. If material is not included in the article's Creative Commons licence and your intended use is not permitted by statutory regulation or exceeds the permitted use, you will need to obtain permission directly from the copyright holder. To view a copy of this licence, visit http://creativecommons.org/licenses/by/4.0/. The Creative Commons Public Domain Dedication waiver (http://creativeco mmons.org/publicdomain/zero/1.0/) applies to the data made available in this article, unless otherwise stated in a credit line to the data. 
and dislocation [3, 4], early implant failure [5], abductor weakness $[4,6]$ and leg length discrepancy [7]. Accurate reconstruction of hip offset (HO) and leg length demonstrated an additive effect on postoperative clinical outcome [8]. Patients with accurate to slightly increased HO combined with balanced leg length show higher increases in delta Harris hip score (HHS) [8]. A postoperative leg length difference (LLD) and difference in $\mathrm{HO}$ above $5 \mathrm{~mm}$ are additionally associated with altered gait kinematics [9].

The anatomical shape of the proximal femur can have a significant impact on postoperative LLD and osseointegration of cementless THA [10]. LLD in cementless straight-stem THA depends on the used implant and its fixation [10]. Dorr type A femurs according to Dorr's classification [11] are $30 \%$ more likely to gain more than $5 \mathrm{~mm}$ of leg length compared to Dorr type $\mathrm{B}$ or $\mathrm{C}$ femurs [12]. A higher canal flare index (CFI) corresponded with an odds ratio of 4.5 in cementless femoral stems with metaphyseal fixation for postoperative $L L D \geq 5 \mathrm{~mm}$, while cementless diaphyseal fixation or cemented stems did not show an increased risk [13].

Cementless short stems have been increasingly used in recent years parallel with the use of minimally invasive approaches $[14,15]$. Short stems allow an accurate reconstruction of hip offset while keeping LLD at a minimum [16]. While the influence of the morphology of the proximal femur has been evaluated in previous studies, the influence in cementless short-stem THA has not been fully evaluated. Therefore, we conducted this study to evaluate the influence of the proximal femoral morphology on offset reconstruction, leg length difference and implant positioning in THA with a cementless short stem with meta-diaphyseal fixation.

\section{Methods}

\section{Patients}

This retrospective radiological comparative study includes patients of a consecutive series of THAs with the same cementless curved short stem (Fitmore ${ }^{\circledR}$ stem, ZimmerBiomet, Warsaw, IN, USA) and bi-hemispherical press-fit acetabular cup (Allofit ${ }^{\circledR} /-\mathrm{S}$, ZimmerBiomet, Warsaw, IN, USA) performed via a minimally invasive supine anterolateral approach. Fitmore ${ }^{\circledR}$ hip stem is a titanium alloy stem ( $\mathrm{Ti}$ Al6V4) that has a porolock Ti-VPS coating in the proximal part to enhance bone ingrowth and is available in four different neck angle options $\left(127^{\circ}, 129^{\circ}, 137^{\circ}, 140^{\circ}\right)$ and 14 different sizes (size 1-14) for each offset option [14]. A cementless titanium press-fit cup with or without screws $\left(\right.$ Allofit $^{\circledR} /-\mathrm{S}$, ZimmerBiomet, Warsaw, IN, USA) was used in all patients. Fitmore $^{\circledR}$ hip stem is available in four different offset options, and therefore, the stem allows an offset reconstruction independent of stem size with superior balance of soft tissue of the hip [17]. The curved design of Fitmore ${ }^{\circledR}$ stem is designed to transmit load proximally and thus to give an optimal fit in the calcar region [18]. The stem has a triple-tapered design to achieve press-fit fixation at the metaphyseal/diaphyseal level and according to the recommended femoral neck resection level [19].

A consecutive series of 1052 hips in 982 patients with index surgery between 2014 and 2019 were screened for inclusion, and the medical records until 90 days postoperative were evaluated. The preoperative X-rays of the pelvis (both hips in comparison, anterior-posterior view, standing upright) were screened for unilateral THA. Diagnoses for inclusion were primary osteoarthritis, avascular necrosis of the femoral head or mild dysplasia of the hip (Crowe I) [20]. Exclusion criteria were defined as bilateral hip disease (Kellgren-Lawrence > grade 1) [21], a history of prior hip surgery, previous trauma, postoperative complication, reoperation or revision for any reason as well as missing pre- or postoperative radiographs. In total, 106 patients met the inclusion criteria (see Fig. 1). The included patients were then reviewed independently by two reviewers (M.L. and C.S.), who were not involved in the index surgery. The anatomical shape of the proximal femur was determined according to the Dorr classification [11]. In case of different determination of Dorr types between both reviewers, the preoperative X-ray was evaluated together and a consensus agreement was found.

Radiographic measurements were performed on preand 3 months postoperative low-centered anteroposterior (AP) radiographs of the pelvis in both groups. Preoperative age at operation, gender, body mass index (BMI) and laterality were recorded. The patient demographics are shown in Table 1.

The study was approved by the institutional review board (EK-No.: 1239/2019). Due to the retrospective study design with evaluation of pre-existing medical records, an informed consent was not required. All procedures performed in studies involving human participants were in accordance with the ethical standards of the institutional and/or national research committee and with the 1964 Helsinki declaration and its later amendments or comparable ethical standards.

\section{Surgical technique and treatment protocol}

Surgical procedures were carried out at the author's institution by surgeons with different levels of experience including 11 consultants and 7 residents. All consultants perform more than 50 , all senior consultants more than 100 arthroplasties per year. Resident surgeries were done under the guidance of a consultant. In all 


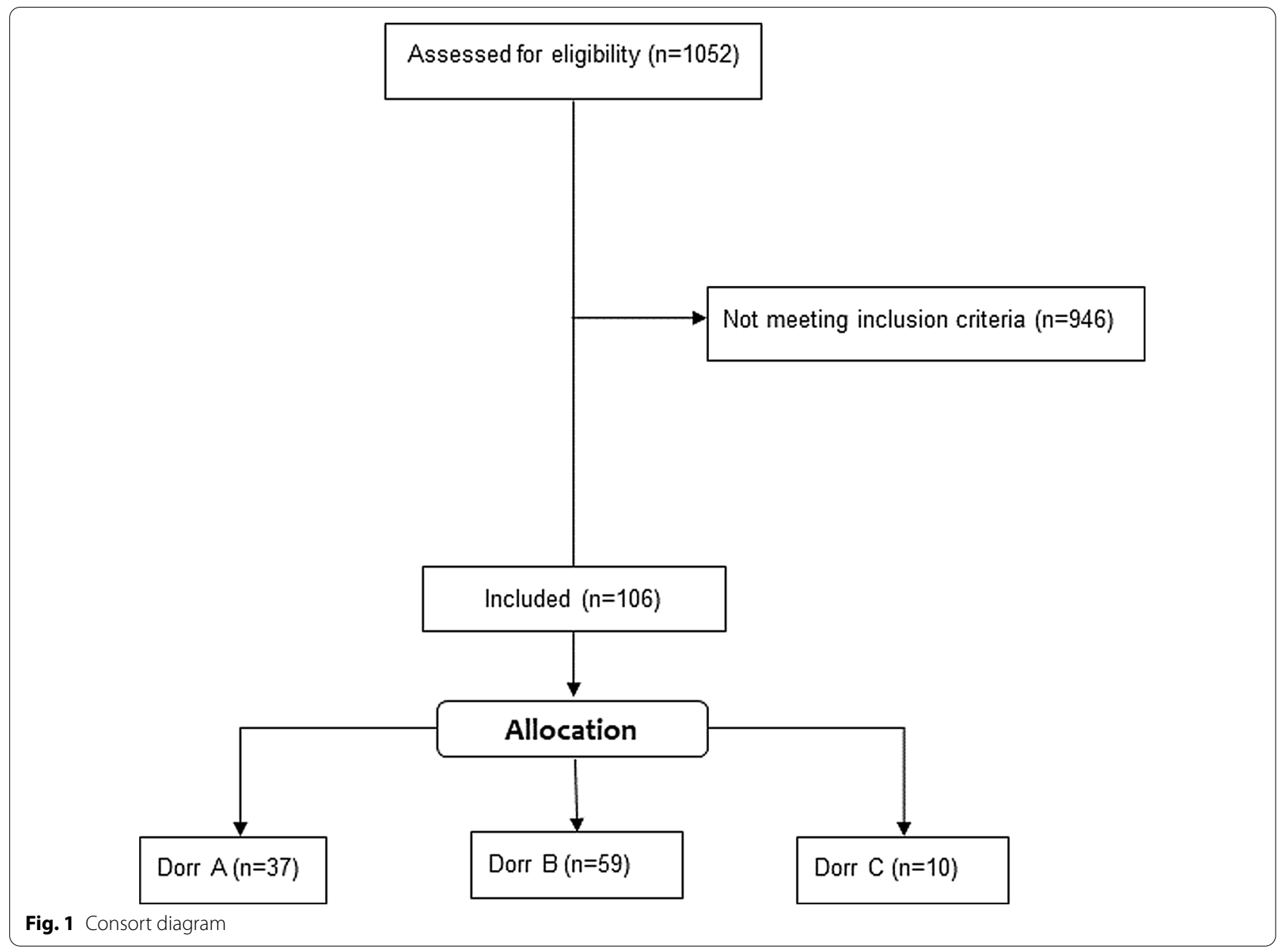

cases, a minimally invasive anterolateral Watson-Jones approach in supine position on a standard operating table under laminar airflow was performed. Extremity preparation was performed with threefold antiseptic scrub with alcohol disinfectant. Draping with a sterile adhesive surgical iodine film was used. The skin incision was centered over the greater trochanter. An incision at the border between the tensor fasciae latae and the tractus iliotibialis was performed. Then, the WatsonJones interval between tensor fasciae latae and gluteus medius was bluntly dissected. A capsulectomy was performed in every case. The standardized peri- and postoperative protocol was identical in all cases, including single-shot antibiotics (Cefuroxime $1.5 \mathrm{~g}$ i.v. directly preoperative), weight-bearing as tolerated from the first postoperative day on, Indomethacin $75 \mathrm{mg}$ daily for the prevention of heterotopic ossification on day 1-4 postoperatively and $40 \mathrm{mg}$ low-molecular weight heparin or Rivaroxaban $10 \mathrm{mg}$ for 28 days postoperatively as venous thromboembolic event prophylaxis.

\section{Radiographic evaluation}

Radiographic measurement was performed on preoperative and 3 months postoperative digital low-centered AP radiographs of the pelvis [22]. Measurement was conducted independently by two reviewers (M.L. and C.S.), who were not involved in the index surgery. Radiographs were taken with the patient in standing position and with both legs in $15^{\circ}$ internal rotation, and the central beam was directed on the symphysis pubis [23]. In order to achieve an accurate measurement of the hip anatomy, a double coordinate system was applied on both the preoperative and the postoperative images [24, 25]. Radiographic analysis was performed using Medi$\mathrm{CAD}^{\circledR}$ Software V5.1 (Hectec GmbH, Altdorf, Germany). To characterize the anatomical shape of the proximal femur and the thickness of cortical bone, the canal-tocalcar ratio and the cortical index $(\mathrm{CI})$ according to Dorr et al. [11] were determined. A high CI indicates a thick cortical bone [11]. Additionally, the canal flare index (CFI) according to Noble et al. [26] was determined. 
Table 1 Patient demographics, pre- and postoperative measurements

\begin{tabular}{|c|c|c|c|c|}
\hline & Dorr A $(n=37)$ & Dorr B $(n=59)$ & Dorr C $(n=10)$ & $P$ value \\
\hline Gender (m/f) & $23: 14$ & 18:41 & $0: 10$ & $<0.001$ \\
\hline Age (in years) & $55.3 \pm 10.6$ & $58.5 \pm 11.3$ & $55.5 \pm 12.0$ & 0.163 \\
\hline Side $(l / r)$ & 18:19 & $25: 34$ & $6: 4$ & 0.547 \\
\hline $\mathrm{BMI}\left(\mathrm{kg} / \mathrm{m}^{2}\right)$ & $29.0 \pm 5.4$ & $26.9 \pm 4.5$ & $26.7 \pm 4.9$ & 0.161 \\
\hline \multicolumn{5}{|c|}{ Preoperative measurements } \\
\hline FO difference (mm) & $1 \pm 4.2$ & $2.3 \pm 3.9$ & $3.3 \pm 4.6$ & 0.157 \\
\hline AO difference $(\mathrm{mm})$ & $0.4 \pm 2.4$ & $0.9 \pm 4.1$ & $1.9 \pm 1.7$ & 0.209 \\
\hline HO difference (mm) & $0.6 \pm 3.8$ & $1.4 \pm 4.1$ & $4.1 \pm 4.8$ & 0.573 \\
\hline $\operatorname{LLD}(\mathrm{mm})$ & $-4.5 \pm 5.5$ & $-3.5 \pm 4.4$ & $-3 \pm 4.3$ & 0.520 \\
\hline CCD angle $\left(^{\circ}\right)$ & $129.8 \pm 5.5$ & $131.3 \pm 6.4$ & $138.1 \pm 7.1$ & 0.007 \\
\hline Canal flare index & $4.3 \pm 0.6$ & $3.8 \pm 0.5$ & $3.1 \pm 0.4$ & $<0.001$ \\
\hline Cortical index & $0.64 \pm 0.04$ & $0.59 \pm 0.03$ & $0.51 \pm 0.05$ & $<0.001$ \\
\hline Canal-to-calcar ratio & $0.54 \pm 0.08$ & $0.58 \pm 0.05$ & $0.68 \pm 0.05$ & $<0.001$ \\
\hline \multicolumn{5}{|c|}{ Postoperative measurements } \\
\hline FO difference (mm) & $5.3 \pm 6.4$ & $7.1 \pm 6.6$ & $9.7 \pm 6.9$ & 0.243 \\
\hline AO difference $(\mathrm{mm})$ & $-2.7 \pm 4.9$ & $-4.2 \pm 4.2$ & $-5.6 \pm 3.6$ & 0.106 \\
\hline HO difference (mm) & $2.6 \pm 4.9$ & $2.9 \pm 5.4$ & $4.1 \pm 7.5$ & 0.698 \\
\hline $\operatorname{LLD}(\mathrm{mm})$ & $-0.38 \pm 5$ & $-0.31 \pm 5.2$ & $1.6 \pm 4.9$ & 0.532 \\
\hline Stem alignment $\left({ }^{\circ}\right)$ & $4.9 \pm 3$ & $4.5 \pm 3.1$ & $4.3 \pm 3.4$ & 0.705 \\
\hline Canal Fill Index I (\%) & $76.7 \pm 6.5$ & $78.9 \pm 6$ & $78.6 \pm 7.6$ & 0.321 \\
\hline Canal fill index II (\%) & $79.6 \pm 7.3$ & $81.5 \pm 5.8$ & $80.6 \pm 10.5$ & 0.411 \\
\hline Canal fill index III (\%) & $84.6 \pm 9.2$ & $83.5 \pm 7.4$ & $78.3 \pm 12.9$ & 0.478 \\
\hline
\end{tabular}

Bold values signal statistically significant values in testing

Radiographic leg length discrepancy (LLD) was measured as the perpendicular distance between line TT and the middle of the lesser trochanter (LT) [23]. The hip center of rotation (COR) was defined using a circle tool determining the diameter of the femoral head and its center [27]. The femoral offset (FO) was determined as the perpendicular distance between the COR and the proximal femoral shaft axis (FSA) [22, 27]. Acetabular offset (AO) was measured as the perpendicular distance between the COR and line $\mathrm{T}$, with $\mathrm{T}$ being the perpendicular line on the transteardrop line (TT) through the ipsilateral teardrop figure [22]. Hip offset (HO) was calculated as the sum of FO and AO [22]. Centrum-collum-diaphyseal (CCD) angle was determined according to M. E. Müller on the affected hip [28]. The stem alignment was measured as the difference in degrees between the anatomic femoral shaft axis and the vertical stem axis [29]. The canal fill indices I, II and III (CFI I; CFI II; CFI III) were determined to evaluate the metaphyseal/diaphyseal filling of the femoral canal by the cementless stem implant on 3 different heights (CFI I: at the level of the LT, CFI II: $1 \mathrm{~cm}$ below the LT, and CFI III: $3 \mathrm{~cm}$ below the LT). On each height, the horizontal diameter of the stem implant was measured and divided by the endosteal medullary canal diameter, multiplied by 100 to achieve the relative percentage [16]. On preoperative $\mathrm{X}$-rays, $\mathrm{FO}, \mathrm{AO}, \mathrm{HO}$ and LLD were measured bilaterally, while CCD angle, CI, canal flare index and canal-to-calcar ratio were measured unilaterally on the affected hip. Complete preoperative measurements are also shown in Fig. 2.

On postoperative X-rays, $\mathrm{FO}, \mathrm{AO}, \mathrm{HO}$ and LLD were measured bilaterally, and stem alignment, CFI I, CFI II and CFI III were measured unilaterally on the operated hip. Complete postoperative measurements are also shown in Fig. 3.

Intra- and interobserver reliabilities were calculated for 15 randomly selected cases for each group. Intraclass correlation coefficients (ICC) were used with a two-way random effects model for absolute agreement. Repeated measurements for intraobserver reliability were performed at day 1 and day 14 in a blinded fashion.

\section{Statistics}

Descriptive statistical analysis was conducted for age, gender, body mass index (BMI) and laterality. A Shapiro-Wilk test was performed for testing for normal distribution. As not all variables were normally distributed, nonparametric testing was performed. For patient demographics, a Fisher's exact test was performed on categorical variables (gender and side). A Kruskal-Wallis test was 


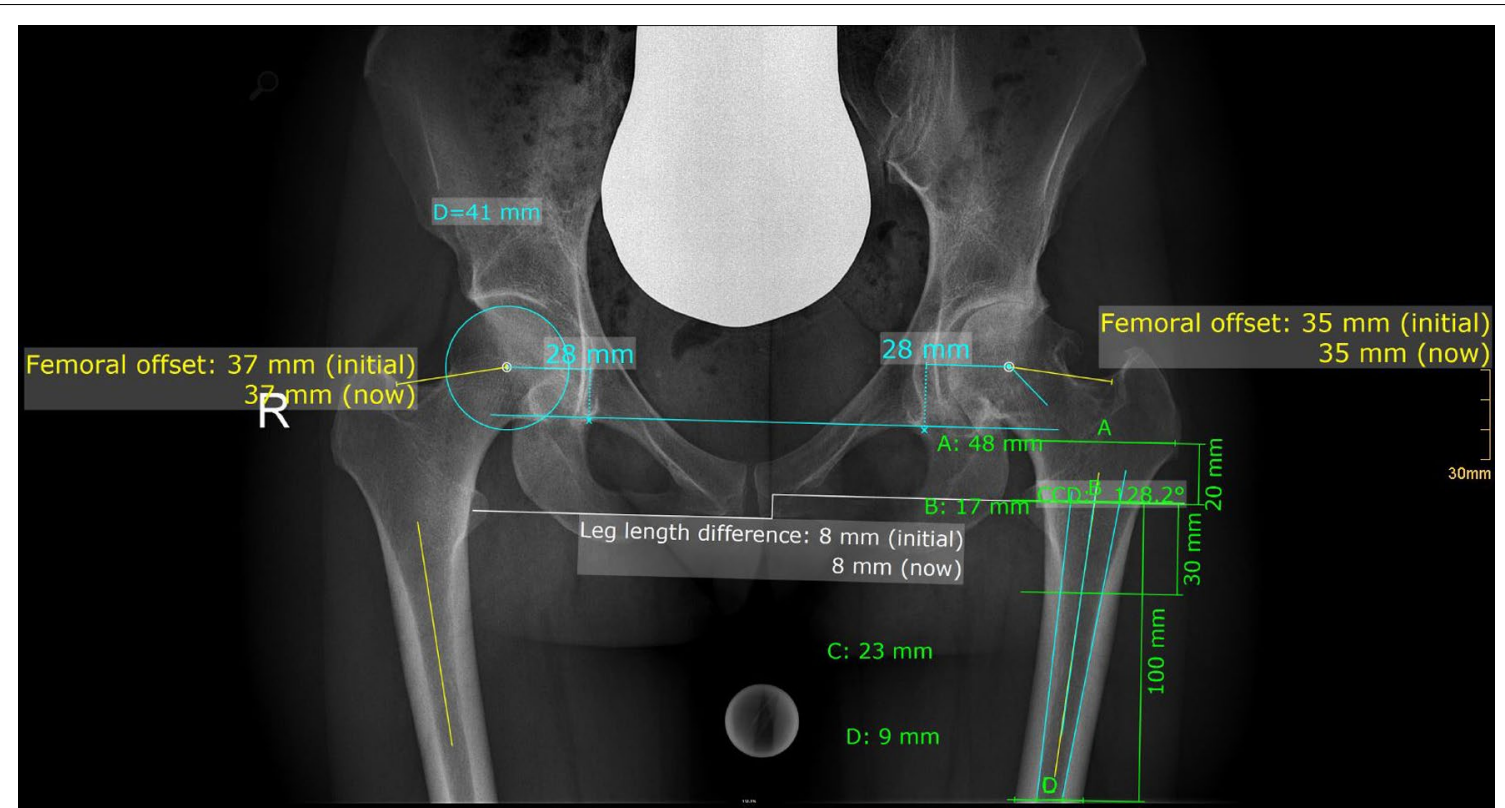

Fig. 2 Preoperative measurements: Both sides: Femoral offset (FO), acetabular offset (AO), vertical position of the center of rotation (COR), leg length difference (LLD); affected hip: centrum-collum-diaphyseal angle (CCD angle), cortical index (Cl), canal flare index, canal-to-calcar ratio

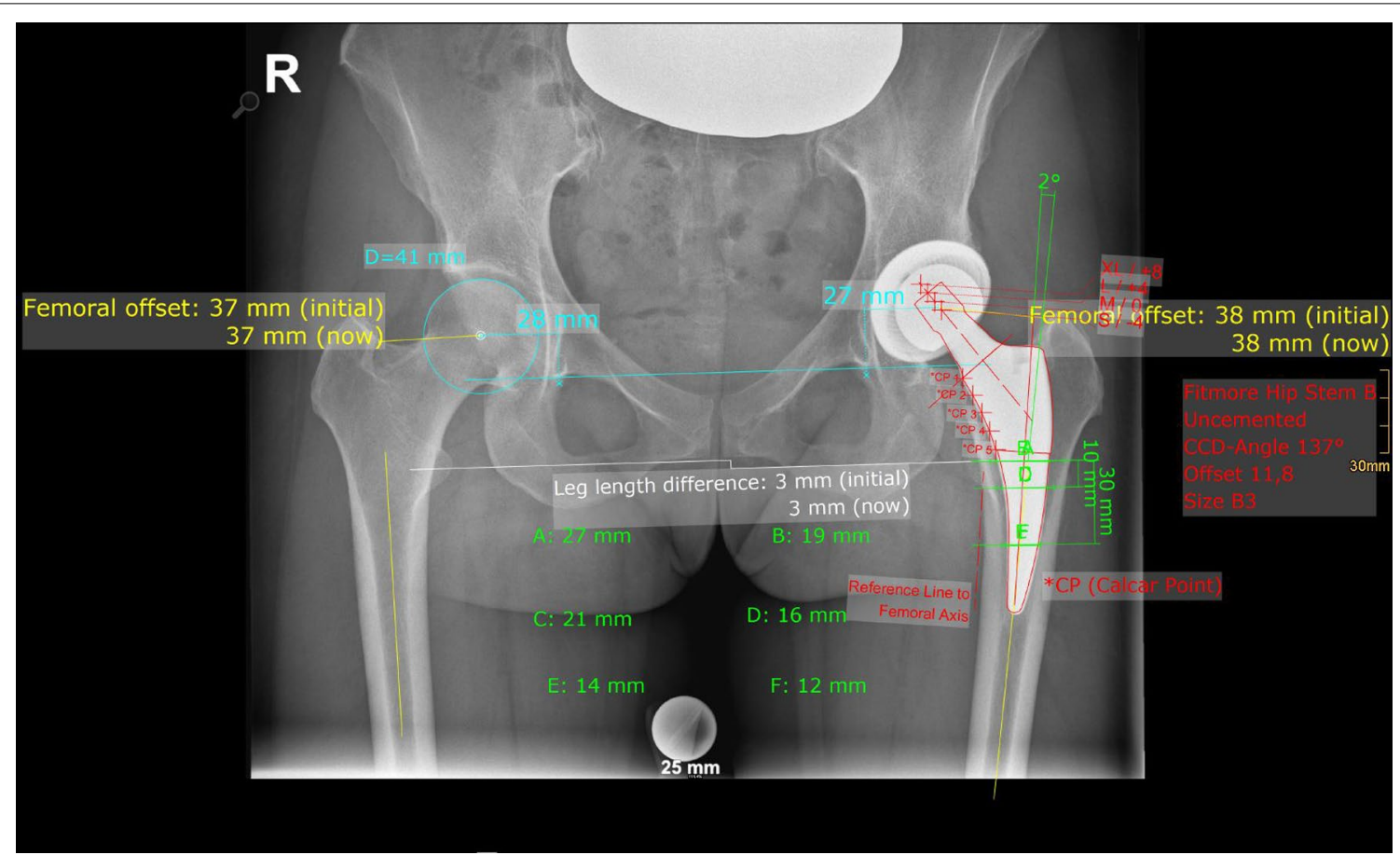

Fig. 3 Postoperative measurements: Both sides: Femoral offset (FO), acetabular offset (AO), vertical position of the center of rotation (COR), leg length difference (LLD); affected side: stem alignment, canal fill indices I, II and III, cup inclination, cup anteversion

performed on continuous variables (age and BMI). For statistical analysis of pre- and postoperative radiographic measurements, a nonparametric Kruskal-Wallis test was performed. Power analysis was not performed due to the observed statistical significance [30]. The impact of the anatomical shape of the proximal femur on LLD and HO 
was evaluated with binary logistic regression models with the same confounding variables (Dorr type, canal flare index, cortical index, calcar-to-isthmus ratio, CCD angle, age, gender, BMI, surgeon's experience, offset option, stem size and varus stem alignment). Binary output variables were defined according to the threshold value ( $L L D \geq 5 \mathrm{~mm} ; \mathrm{LLD} \geq 10 \mathrm{~mm} ; \mathrm{HO} \geq 5 \mathrm{~mm} ; \mathrm{HO} \geq 10 \mathrm{~mm}$ ). Logistic regression for surgeon's experience was evaluated by forming two groups: consultants; residents. Statistical analysis was calculated with SPSS version 27 (IBM SPSS statistics, Chicago, IL, USA). A $p$ value $<0.05$ was considered as statistically significant.

\section{Results}

The overall interclass correlation coefficient between the 2 sets of measurements was $0.991 \%$ (95\% confidence interval, 0.988-0.993, $p<0.001$ ).

Patient demographics are shown in Table 1. Of the 106 included patients, 37 patients (34.9\%) were addressed to Group A (Dorr type A), 59 patients (55.7\%) to Group B (Dorr type B) and 10 patients (9.4\%) to Group C (Dorr type $C$ ). There was no difference in patient demographics regarding age, BMI and operated side. The groups differed in gender distribution with significantly higher female predominance in Dorr types B and C $(p<0.001)$.

Preoperative measurements are shown in Table 1. The Dorr types were significantly different in canal flare index $(p<0.001)$, cortical index $(p<0.001)$ and canal-to-calcar ratio $(p<0.001)$. Dorr types A and B showed significantly lower CCD angles $(p=0.007)$ compared to Dorr type C. Postoperative measurements are also shown in Table 1. There was no significant difference detectable in all groups.
Logistic regression for LLD is shown in Table 2. For both thresholds (LLD $\geq 5 \mathrm{~mm}$; LLD $\geq 10 \mathrm{~mm}$ ), a significant risk was not detectable.

Logistic regression for $\mathrm{HO}$ is shown in Table 3. Using a higher offset option was a risk factor for an increased $\mathrm{HO} \geq 5 \mathrm{~mm}$ compared to the contralateral healthy hip $(\mathrm{OR}=2.252$; $\mathrm{CI}: 1.069-4.745 ; p=0.033)$. For all other parameters, a significantly increased risk was not detectable. For the threshold LLD $\geq 10 \mathrm{~mm}$, there were no significant differences detectable for all parameters tested in logistic regression.

\section{Discussion}

The morphology of the proximal femur was not identified as a risk factor for a LLD $\geq 5 \mathrm{~mm}$ and $\geq 10 \mathrm{~mm}$ as well as an increase of $\mathrm{HO} \geq 5 \mathrm{~mm}$ and $\geq 10 \mathrm{~mm}$ in short-stem THA. The femoral shape according to Dorr classification as well as CFI, CI and canal-to-calcar ratio did not pose an increased for risk for a LLD and an increased $\mathrm{HO}$ above $5 \mathrm{~mm}$ or $10 \mathrm{~mm}$ compared to a contralateral healthy hip.

Postoperative LLD can affect the functional outcome after THA adversely [10]. A LLD $\leq 5 \mathrm{~mm}$ and an increase in $\mathrm{HO} \leq 5 \mathrm{~mm}$ are seen to be beneficial for postoperative clinical outcome in cementless THA [8]. Postoperative clinical outcome decreases with every $5 \mathrm{~mm}$ increase in $\mathrm{HO}$ and LLD [8]. Additionally, a LLD greater than $7-10 \mathrm{~mm}$ is often perceived by patients [31]. Brumat et al. [13] detected higher CFI as a risk factor for LLD $\geq 5 \mathrm{~mm}$ with an odds ratio of $4.5(p=0.03)$ in cementless THA with metaphyseal fixation, while diaphyseal and cemented fixation did not show an increased risk. CFI was not detected as a risk factor in the presented study in cementless short-stem THA for HO and LLD.

Table 2 Binary logistic regression for $L L D \geq 5 \mathrm{~mm}$ and $L L D \geq 10 \mathrm{~mm}$

\begin{tabular}{|c|c|c|c|c|}
\hline & \multicolumn{2}{|l|}{$\mathrm{LLD} \geq 5$} & \multicolumn{2}{|l|}{$\mathrm{LLD} \geq 10$} \\
\hline & Odds ratio $(\mathrm{CI})$ & $P$ value & Odds ratio $(\mathrm{Cl})$ & $P$ value \\
\hline Dorr type & $0.543(0.211-1.397)$ & 0.205 & $3.711(0.148-93.243)$ & 0.425 \\
\hline Canal flare index & $2.264(0.634-8.086)$ & 0.208 & $1.085(0.29-41.101)$ & 0.965 \\
\hline Cortical index & $1.053(0.361-3.065)$ & 0.925 & $1.806(0.131-25.002)$ & 0.659 \\
\hline Canal-to-calcar ratio & $0.711(0.372-1.360)$ & 0.302 & $0.299(0.029-3.076)$ & 0.310 \\
\hline CCD angle & $0.987(0.915-1.066)$ & 0.742 & $0.888(0.727-1.084)$ & 0.243 \\
\hline Age & $1.031(0.990-1.074)$ & 0.141 & $0.904(0.757-1.079)$ & 0.263 \\
\hline Gender & $0.826(0.283-2.409)$ & 0.727 & $0.173(0.004-8.358)$ & 0.375 \\
\hline BMI & $0.965(0.882-1.056)$ & 0.437 & $0.850(0.604-1.197)$ & 0.352 \\
\hline Surgeon's experience & $0.931(0.389-2.226)$ & 0.872 & $0.996(0.046-21.329)$ & 0.998 \\
\hline Offset option stem & $1.484(0.744-2.958)$ & 0.262 & $0.137(0.014-1.317)$ & 0.085 \\
\hline Stem size & $0.942(0.730-1.216)$ & 0.647 & $1.931(0.833-4.477)$ & 0.125 \\
\hline Varus stem alignment & $0.395(0.149-1.046)$ & 0.061 & $1.994(0.146-27.263)$ & 0.605 \\
\hline
\end{tabular}


Table 3 Binary logistic regression for $\mathrm{HO} \geq 5 \mathrm{~mm}$ and $\mathrm{HO} \geq 10 \mathrm{~mm}$

\begin{tabular}{|c|c|c|c|c|}
\hline & \multicolumn{2}{|l|}{$\mathrm{HO} \geq 5$} & \multicolumn{2}{|l|}{$\mathrm{HO} \geq 10$} \\
\hline & Odds ratio $(\mathrm{Cl})$ & $P$ value & Odds ratio $(\mathrm{Cl})$ & $P$ value \\
\hline Dorr type & $1.497(0.566-3.959)$ & 0.417 & $1.875(0.414-8.493)$ & 0.415 \\
\hline Canal flare index & $0.390(0.105-1.448)$ & 0.160 & $0.381(0.057-2.573)$ & 0.322 \\
\hline Cortical index & $1.703(0.559-5.190)$ & 0.349 & $1.219(0.238-6.242)$ & 0.812 \\
\hline Canal-calcar ratio & $1.364(0.698-2.666)$ & 0.363 & $1.114(0.392-3.163)$ & 0.840 \\
\hline CCD angle & $0.981(0.904-1.064)$ & 0.640 & $0.981(0.874-1.101)$ & 0.745 \\
\hline Age & 1.019 (0.976-1.064) & 0.396 & $1.009(0.946-1.077)$ & 0.780 \\
\hline Gender & $0.951(0.307-2.939)$ & 0.930 & $1.018(0.204-5.088)$ & 0.983 \\
\hline $\mathrm{BMI}$ & $0.994(0.906-1.091)$ & 0.902 & $0.970(0.834-1.127)$ & 0.689 \\
\hline Surgeon's experience & $0.729(0.287-1.854)$ & 0.507 & $0.565(0.109-2.929)$ & 0.496 \\
\hline Offset option stem & $2.252(1.069-4.745)$ & 0.033 & $1.546(0.487-4.903)$ & 0.460 \\
\hline Stem size & $0.989(0.754-1.298)$ & 0.936 & $1.048(0.694-1.581)$ & 0.825 \\
\hline Varus stem alignment & $1.378(0.506-3.758)$ & 0.531 & $2.759(0.507-15.000)$ & 0.240 \\
\hline
\end{tabular}

Bold value signal statistically significant values in testing

Lim et al. [12] report the risk of leg length increase in Dorr type A femurs and the risk of leg length decrease in Dorr type $\mathrm{C}$ femurs in cementless straight-stem THA. A higher cortical index $(\mathrm{CI})$ as found in Dorr type A femurs shows a significantly higher LLD $(p=0.003)$ [12]. We did not detect a significant difference in LLD depending on Dorr type $(p=0.532)$ in short-stem THA. Also, logistic regression did not show any significantly increased risk for LLD depending on Dorr type or CI. Testing for differences in LLD as well as logistic regression for Dorr type, CFI, CI and canal-to-calcar ratio did not show differences or a significantly increased risk for a LLD $\geq 5 \mathrm{~mm}$ or $\geq 10 \mathrm{~mm}$. Therefore, we conclude that the shape of the proximal femur does not pose a risk for LLD in cementless short-stem THA with a meta-diaphyseal short stem.

In order to evaluate possible confounder, we also carried out the logistic regression for other variables such as age, gender or BMI. Warnock et al. [32] detected a lengthening in cementless THA in females due to a greater femoral height discrepancy leading to reduced delta gain in Oxford hip score (OHS) and pain scores. AlAmiry et al. [33] detected a negative effect of increased BMI in restoration of leg length but not on restoration of femoral offset. In our study, we could not detect a significantly increased risk for increased LLD and HO for gender and BMI. Besides patient demographics, we also evaluated offset option, size of the implanted stem and varus stem alignment as possible confounder. We could not detect any increased risk for increased postoperative LLD. We could only detect a significant risk for increased $\mathrm{HO} \geq 5 \mathrm{~mm}$ by using higher offset options.

Surgeon's experience is also a confounding factor in maintaining leg length in THA. Kishimoto et al. [34] found out that $80 \%$ of patients operated by high-volume surgeons had a LLD $<5 \mathrm{~mm}$ compared to $40 \%$ of patients operated by low-volume surgeons. Low-volume surgeons are a risk factor for increased postoperative LLD with an odds ratio of 8.26 [34]. We evaluated LLD and reconstruction of $\mathrm{HO}$ according to surgeon's experience by evaluating differences between consultants and residents. We did not find a significantly increased risk for increased postoperative LLD or increased HO in THA performed by less experienced surgeons.

We also evaluated stem sizing and implant positioning. Stem alignment and canal fill indices were without significant difference in all Dorr types. Apart from that, high CFI is also seen as a risk factor of femoral component undersizing, particularly with taper wedge stems, due to potting the stem distally in the narrow canal. We could not detect a negative on stem sizes without any statistical significance for canal fill indices [35]. A canal fill index $<80 \%$ is seen as undersized in cementless straight-stem THA [35]. Comparable canal fill indices for Fitmore ${ }^{\circledR}$ hip stem show higher values with a canal fill indices between $85.2 \%$ and $90.4 \%$ [16]. We report lower values between 76.7 and $84.6 \%$. However, the anatomical shape of the proximal femur was not a risk factor for implant undersizing in the presented study. The generally lower canal fill indices are more likely to be a result of less aggressive broaching and accepting lower canal fill. The long-term effect of lower canal fill indices for short stems has not been evaluated fully. However, the anatomical shape of the proximal shape does not pose a risk factor for implant undersizing of the femoral component.

Several limitations of the study have to be addressed. Firstly, we tried to minimize a potential selection bias 
with very strict inclusion criteria. Only patients with a single implant design and approach were included in this study. A homogenous study cohort was created by excluding patients with a bilateral hip disease (Kellgren-Lawrence $>$ grade 1). Apart from gender distribution, there were not any significant differences between the three different study groups for age at surgery, BMI or side. Also, measurements of preoperative differences in $\mathrm{FO}, \mathrm{AO}$ and $\mathrm{HO}$ as well as LLD were carried out without any significance. Furthermore, we aimed to increase reliability of the measurements and results by restricting inclusion based on preoperative diagnosis. We excluded all forms of secondary osteoarthritis of the hip and development dysplasia of the hip Crowe grade II to IV. Prior surgery before THA was also excluded. However, mild hip dysplasia (lateral center-edge angle $20^{\circ}-25^{\circ}$ ), coxa profunda and morphologic alterations related to cam- or pincer-type impingement were included, because these changes might be subtle and cannot be reliably identified in the present study cohort with end-stage disease. Therefore, we conclude that the findings in the present study are applicable for primary osteoarthritis and care must be taken when applying our findings on secondary osteoarthritis or high grades of development dysplasia of the hip. Secondly, we address the fact of taking measurements on plain radiographs. FO is underestimated by approximately $13 \%$ on plain radiographs [27]. Additionally, radiographic measurement of leg length difference does not necessarily reflect clinical leg length difference [36]. Additionally, in radiographic measurements the potential disadvantage of malpositioning the patient in the X-ray beam or malrotation of the pelvis and femur is potential factors for disadvantage in accuracy. However, our measurements are easily reproducible, applicable in daily routine and less invasive regarding radiation exposure. Furthermore, we postulate variances in inter- and intraobserver reliability in measuring clinical leg length difference.

\section{Conclusion}

The anatomical shape of the proximal femur has no negative influence on the reconstruction of hip offset and leg length difference in cementless total hip arthroplasty with a curved short stem with meta-diaphyseal fixation. Offset reconstruction and leg length difference are not negatively influenced by Dorr type, canal flare index, cortical index and canal-to-calcar ratio. Additionally, the morphology of the proximal femur does not lead to stem undersizing or higher varus stem positioning.

\section{Abbreviations}

HO: Hip offset; THA: Total hip arthroplasty; LLD: Leg length difference; HHS: Harris hip score; CFI: Canal Flare Index; AP: Anteroposterior; BMI: Body mass index; Cl: Cortical index; LT: Lesser trochanter; COR: Center of rotation; FO: Femoral offset; FSA: Femoral shaft axis; AO: Acetabular offset; TT: Transteardrop line; CCD: Centrum-collum-diaphyseal; CFI I; CFI II; CFI III: Canal fill indices I, II and III; ICC: Intraclass correlation coefficients; OR: Odds ratio; OHS: Oxford hip score.

\section{Acknowledgements \\ Supported by Johannes Kepler Open Access Publishing Fund.}

\section{Authors' contributions}

$M L$ wrote the manuscript, performed the statistical analysis and designed the study, acquisition of data and interpretation of the data. SF was involved in the acquisition of data and interpretation of the data. AK was involved in the acquisition of data and interpretation of the data. TG revised the manuscript. CS jointly conceived the study, performed statistical analysis and edited the manuscript. All authors read and approved the final manuscript.

\section{Funding}

The study was conducted without any funding or benefits from a commercial party. Three co-authors have received or will receive benefits for personal or professional use from a commercial party outside the conduction of this study.

\section{Availability of data and materials}

Data and materials are available on request.

\section{Declarations}

Ethics approval and consent to participate

This study received ethical approval from the local institutional review board of the "Ethikkommission OÖ" of the Johannes Kepler University Linz (JKU Linz) (EK-No.: 1239/2019) in accordance with the World Medical Association Declaration of Helsinki. Because of the retrospective evaluation of pre-existing medical records, an informed consent was not required.

\section{Consent for publication}

Not applicable.

\section{Competing interests}

We report personal fees paid to one co-author (T.G.) during the conduct of the study from Zimmer Biomet, Europe, and from Depuy Synthes Orthopädie Gmbh, Peter Brehm GmbH, ImplanTec GmbH, outside the submitted work. We report research grants paid to our institution during the conduct of the study from Zimmer Biomet, Europe, Mathys AG, Switzerland, Anika Therapeutics, outside the submitted work.

\section{Author details}

${ }^{1}$ Department for Orthopedics and Traumatology, Kepler University Hospital

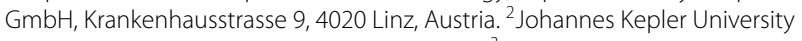
Linz, Altenberger Strasse 69, 4040 Linz, Austria. ${ }^{3}$ Kepler University Hospital Linz, Krankenhausstrasse 9, 4020 Linz, Austria.

Received: 2 November 2021 Accepted: 5 December 2021

Published online: 20 December 2021

\section{References}

1. Judge A, Arden NK, Kiran A, Price A, Javaid MK, Beard D, Murray D, Field RE. Interpretation of patient-reported outcomes for hip and knee replacement surgery: identification of thresholds associated with satisfaction with surgery. J Bone Joint Surg Br. 2012;94(3):412-8.

2. Learmonth ID, Young $C$, Rorabeck $C$. The operation of the century: total hip replacement. Lancet. 2007;370(9597):1508-19.

3. Malik A, Maheshwari A, Dorr LD. Impingement with total hip replacement. J Bone Joint Surg Am. 2007;89(8):1832-42. 
4. McGrory BJ, Morrey BF, Cahalan TD, An KN, Cabanela ME. Effect of femoral offset on range of motion and abductor muscle strength after total hip arthroplasty. J Bone Joint Surg Br. 1995;77(6):865-9.

5. Snijders TE, van Erp JHJ, de Gast A. Restoring femoral offset and leg length; the potential of a short curved stem in total hip arthroplasty. J Orthop. 2019;16(5):396-9.

6. Asayama I, Chamnongkich S, Simpson KJ, Kinsey TL, Mahoney OM. Reconstructed hip joint position and abductor muscle strength after total hip arthroplasty. J Arthroplasty. 2005:20(4):414-20.

7. Konyves A, Bannister GC. The importance of leg length discrepancy after total hip arthroplasty. J Bone Joint Surg Br. 2005;87(2):155-7.

8. Innmann MM, Maier MW, Streit MR, Grammatopoulos G, Bruckner T, Gotterbarm T, Merle C. Additive influence of hip offset and leg length reconstruction on postoperative improvement in clinical outcome after total hip arthroplasty. J Arthroplasty. 2018;33(1):156-61.

9. Renkawitz T, Weber T, Dullien S, Woerner M, Dendorfer S, Grifka J, Weber M. Leg length and offset differences above $5 \mathrm{~mm}$ after total hip arthroplasty are associated with altered gait kinematics. Gait Posture. 2016:49:196-201.

10. Mavcic B, Antolic V. Cementless femoral stem fixation and leg-length discrepancy after total hip arthroplasty in different proximal femoral morphological types. Int Orthop. 2020;45:891-6.

11. Dorr LD, Faugere MC, Mackel AM, Gruen TA, Bognar B, Malluche HH. Structural and cellular assessment of bone quality of proximal femur. Bone. 1993;14(3):231-42.

12. Lim YW, Huddleston JI 3rd, Goodman SB, Maloney WJ, Amanatullah DF. Proximal femoral shape changes the risk of a leg length discrepancy after primary total hip arthroplasty. J Arthroplasty. 2018;33(12):3699-703.

13. Brumat P, Pompe B, Antolic $V$, Mavcic B. The impact of canal flare index on leg length discrepancy after total hip arthroplasty. Arch Orthop Trauma Surg. 2018;138(1):123-9.

14. Gustke K. Short stems for total hip arthroplasty: initial experience with the Fitmore stem. J Bone Joint Surg Br. 2012;94(11 Suppl A):47-51.

15. Khanuja HS, Banerjee S, Jain D, Pivec R, Mont MA. Short bone-conserving stems in cementless hip arthroplasty. J Bone Joint Surg Am. 2014;96(20):1742-52.

16. Innmann MM, Spier K, Streit MR, Aldinger PR, Bruckner T, Gotterbarm T, Merle C. Comparative analysis of the reconstruction of individual hip anatomy using 3 different cementless stem designs in patients with primary hip osteoarthritis. J Arthroplasty. 2018;33(4):1126-32.

17. Yerasimides JG. Use of the Fitmore(R) hip stem bone-preserving system for the minimally invasive anterior-supine approach in hip replacement. Am J Orthop (Belle Mead NJ). 2010;39(10 Suppl):13-6.

18. Maier MW, Streit MR, Innmann MM, Kruger M, Nadorf J, Kretzer JP, Ewerbeck V, Gotterbarm T. Cortical hypertrophy with a short, curved uncemented hip stem does not have any clinical impact during early follow-up. BMC Musculoskelet Disord. 2015;16:371.

19. Innmann MM, Weishorn J, Bruckner T, Streit MR, Walker T, Gotterbarm T, Merle C, Maier MW. Fifty-six percent of proximal femoral cortical hypertrophies 6 to 10 years after Total hip arthroplasty with a short Cementless curved hip stem - a cause for concern? BMC Musculoskelet Disord. 2019;20(1):261.

20. Crowe JF, Mani VJ, Ranawat CS. Total hip replacement in congenital dislocation and dysplasia of the hip. J Bone Joint Surg Am. 1979;61 (1):15-23.

21. Kellgren JH, Lawrence JS. Radiological assessment of osteo-arthrosis. Ann Rheum Dis. 1957;16(4):494-502.

22. Dastane M, Dorr LD, Tarwala R, Wan Z. Hip offset in total hip arthroplasty: quantitative measurement with navigation. Clin Orthop Relat Res. 2011;469(2):429-36

23. Innmann MM, Streit MR, Kolb J, Heiland J, Parsch D, Aldinger PR, Konigshausen M, Gotterbarm T, Merle C. Influence of surgical approach on component positioning in primary total hip arthroplasty. BMC Musculoskelet Disord. 2015;16:180.

24. Kutzner KP, Kovacevic MP, Roeder C, Rehbein P, Pfeil J. Reconstruction of femoro-acetabular offsets using a short-stem. Int Orthop. 2015;39(7):1269-75.

25. Wedemeyer C, Quitmann H, Xu J, Heep H, von Knoch M, Saxler G. Digital templating in total hip arthroplasty with the Mayo stem. Arch Orthop Trauma Surg. 2008;128(10):1023-9.
26. Noble PC, Alexander JW, Lindahl LJ, Yew DT, Granberry WM, Tullos HS. The anatomic basis of femoral component design. Clin Orthop Relat Res. 1988:235:148-65.

27. Merle C, Waldstein W, Pegg E, Streit MR, Gotterbarm T, Aldinger PR, Murray DW, Gill HS. Femoral offset is underestimated on anteroposterior radiographs of the pelvis but accurately assessed on anteroposterior radiographs of the hip. J Bone Joint Surg Br. 2012;94(4):477-82.

28. Waldt S, Eiber M, Wörtler K. Messverfahren und Klassifikationen in der muskuloskelettalen Radiologie. Stuttgart: Thieme; 2011.

29. Aldinger PR, Jung AW, Breusch SJ, Ewerbeck V, Parsch D. Survival of the cementless Spotorno stem in the second decade. Clin Orthop Relat Res. 2009;467(9):2297-304.

30. Hoenig JM, Heisey DM. The abuse of power. Am Stat. 2001;55(1):19-24.

31. O'Brien S, Kernohan G, Fitzpatrick C, Hill J, Beverland D. Perception of imposed leg length inequality in normal subjects. Hip Int. 2010;20(4):505-11.

32. Warnock JM, Karayiannis PN, Gallagher NE, Hill JC, Beverland DE. Are there gender-specific errors in restoration of hip biomechanics that affect outcome following total hip arthroplasty? J Arthroplasty. 2020;35(5):1424-31.

33. Al-Amiry B, Pantelakis G, Mahmood S, Kadum B, Brismar TB, Sayed-Noor AS. Does body mass index affect restoration of femoral offset, leg length and cup positioning after total hip arthroplasty? A prospective cohort study. BMC Musculoskelet Disord. 2019;20(1):422.

34. Kishimoto Y, Suda H, Kishi T, Takahashi T. A low-volume surgeon is an independent risk factor for leg length discrepancy after primary total hip arthroplasty: a case-control study. Int Orthop. 2020;44(3):445-51.

35. Streit MR, Innmann MM, Merle C, Bruckner T, Aldinger PR, Gotterbarm T. Long-term (20- to 25-year) results of an uncemented tapered titanium femoral component and factors affecting survivorship. Clin Orthop Relat Res. 2013;471(10):3262-9.

36. Tipton SC, Sutherland JK, Schwarzkopf R. The assessment of limb length discrepancy before total hip arthroplasty. J Arthroplasty. 2016;31(4):888-92.

\section{Publisher's Note}

Springer Nature remains neutral with regard to jurisdictional claims in published maps and institutional affiliations.

Ready to submit your research? Choose BMC and benefit from:

- fast, convenient online submission

- thorough peer review by experienced researchers in your field

- rapid publication on acceptance

- support for research data, including large and complex data types

- gold Open Access which fosters wider collaboration and increased citations

- maximum visibility for your research: over $100 \mathrm{M}$ website views per year

At BMC, research is always in progress.

Learn more biomedcentral.com/submissions 